\title{
An Exploratory Study of Thai University Students' Understanding of World Englishes
}

\author{
Saksit Saengboon ${ }^{1}$ \\ 1 Graduate School of Language and Communication (GSLC), the National Institute of Development \\ Administration (NIDA), Thailand \\ Correspondence: Saksit Saengboon, Graduate School of Language and Communication (GSLC), the National \\ Institute of Development Administration (NIDA), 118 Serithai Road, Bangkapi, Bnagkok 10240, Thailand. \\ E-mail: saksit2505@gmail.com
}

Received: September 22, 2015 Accepted: October 13, 2015 Online Published: October 14, 2015

doi:10.5539/elt.v8n11p131

URL: http://dx.doi.org/10.5539/elt.v8n11p131

\begin{abstract}
This exploratory study investigated the perceptions of Thai university students towards World Englishes (WEs). One hundred and ninety-eight students from three universities in Bangkok were administered a questionnaire inquiring about definitions of WEs, the Kachruvian concentric circles, the concepts of standard and ownership of English, Thai English and the role of native vs. non-native English speaking teachers. Findings revealed that the majority of the respondents were ambivalent about WEs, although they still prized British and American English as most desirable. However, Thai English was perceived as undesirable, although they did not mind whether Thais may speak English with the Thai accent. Implications for classroom teaching and future research are provided.
\end{abstract}

Keywords: Thai university students, perceptions, world Englishes

\section{Introduction}

Over the past three decades, World Englishes (WEs) (Baker, 2009; Bennui \& Hashim, 2014; Higgins, 2003; Jenkins, 2006; Kachru, 1990; Kirkpatrick, 2012) has been extensively researched in fields that run the gamut of sociolinguistics, discourse analysis, English education and intercultural communication. While it is considered a "realistic" linguistic phenomenon due to its emphasis on a sociolinguistic reality (Yano, 2009), educated laypersons who nevertheless are key stakeholders may not necessarily be aware of its existence. In fact, Jenkins, an ardent advocate of WEs, once remarked that someone pointed out to her, based on the English script she had prepared for an international conference, whether the word "Englishes" was wrongly spelt. Such ignorance, however, is understandable, if not condonable, because to many an educated English speaker, English refers almost exclusively to British or American English at the expense of its Australian, Canadian and New Zealander counterparts, let alone other varieties of English.

For several Thai English educators, the concept of WEs is no stranger. In fact, a 1984 doctoral dissertation conducted in an American university (Chutisilp, 1984) was believed to be the first written work devoted to WEs. It focuses on the role of English in Thailand. Subsequently, in 1986 a group of Thai scholars investigated how English was used in Thailand. (Masavisut et al., 1986). Additional studies by Thai researchers (Buripakdi, 2012; Snodin, 2014) lend strong support to the ever growing recognition of its presence at least in the Thai academic circle. This is commendable from a theoretical and linguistic point of view. However, what has yet to be ascertained is perceptions of younger generations of Thais (e.g., university students) towards WEs. This is because, more than any other group of Thais, they will bear the brunt of the emergence of WEs in their future professions owing to the ever-increasing emergence of diverse workforce (implying varieties of English to be encountered).

Given the paucity of research to date concerning how Thai university students construe the concept of WEs in the Thai context, the purpose of this study is to attempt to fill the gap by investigating perceptions of Thai university students towards WEs and its "place" in Thai society. In this regard, this study seeks to address the 
following research questions:

1) What are perceptions of Thai university students regarding World Englishes?

2) How do such perceptions reflect the participants' understanding of World Englishes?

\section{Focused Literature Review}

\subsection{What Does World Englishes Entail?}

World Englishes, as advanced by Bolton (2004), is capable of various meanings, chief among which is to serve as an umbrella term that includes all existing varieties of English in the world. That is, it could refer to the English spoken by native speakers by birth as much as by those who learn it in a classroom setting with severely limited use of English in everyday life. In this respect, WEs focuses not only on linguistic features of those varieties of English but also on such issues as identity (Kumaravadivelu, 2012), mutual intelligibility (Nelson, 2011), and pedagogical options (Nelson \& Kern, 2012).

The non-linguistic components mentioned above allude to the fact that WEs is a new sociolinguistic paradigm that attempts to empower the so-called non-native speakers of English who have long been subjected to the inferior status of speaking English as a "second" language at best or a "foreign" language at worst. In other words, WEs is democratic in nature; anyone who speaks English should be the rightful owner of the language, albeit with starkly different accents and forms and hence "dignity."

With its focus on language rights equality, WEs also emphasizes that standard English must necessarily be construed context by context. Holding on to a particular standard-be it British or American is a futile effort. However, much like any other social concept, WEs with its emphasis on English users' empowerment presents a double-edged sword, for concerns arise as to how far we can go in allowing for varieties of English to emerge. It is suggested that certain core characteristics of English must be kept intact, otherwise all those varieties will end up stifling communication efforts on the part of those who speak it-very much in the same fashion as "too many cooks spoil the broth."

Therefore, it is no exaggeration to state that WEs could be capable of enabling "free" speakers as much as inhibiting successful communication if it is not reined in in a timely manner. Because of this paradoxical nature of WEs, it is necessary to study perceptions of English speakers, notably non-native speakers such as Thai students, so that we can achieve a better understanding of this increasingly relevant linguistic phenomenon.

As regards WEs, several models have been proposed in an attempt to characterize key aspects of WEs such as Kachru's (1992) Three Concentric Circles; Mondiano's (1999b) English as an international language model; Pennycok's (2009) 3D transtextual model of English use; Yano's (2009) three-dimensional model of English use and Mahboob and Liang's (2014) language variation framework. While these models have differed in their emphases concerning either language use or users, they have shared more or less the same objective, which is to realistically and pragmatically describe how the English language has been used, which is by no means restricted to the Inner Circle norms of usage. In other words, WEs and its accompanying element, English as a Lingua Franca (ELF), focus on what Baker (2009) calls "linguaculture" (p. 569) defined as “... the manner in which a language is learned as meaning-making cultural practice in a specific sociocultural context" (p. 569). In fact, as Cogo (2008) put it, ELF “... describes the diversity and appropriacy of use in specific local and lingua franca contexts of use" (p. 58). In a nutshell, WEs and ELF are intended to describe rather than prescribe the ways in which English is being used today.

\subsection{Selected Studies on World Englishes vis-à-vis Thai Speakers of English}

Baker (2009) examined the relationship between English and culture within the English as a lingua franca (ELF) framework by focusing on how a group of Thai university students went about communicating in English in a Thai university. Salient findings reported are that the Thai participants had been found to engage actively in speaking their own versions of English without any concern for "standard" British or American English. More importantly, they were observed to get involved in a culture that was neither their own culture nor the culture of English native-speaking peoples but a third-place culture, one that identifies with neither L1 nor L2. This underscores the widespread role of ELF.

Shifting to a written mode of ELF, Glass (2009) conducted a survey to learn more about the participants' motive in using English in communicating with other fellow Thais in Thai society, it was reported that several participants opted for English as mode of written communication because it was more convenient for them to 
express their thoughts in English, although other findings were quite expected namely they wanted to practice English. Given the findings, it could be concluded that English, especially ELF, is becoming more widespread and more relevant in communication among Thais.

In a similar vein, Troyer (2012) studied the role of English in the Thai linguistic netscape, another key platform for ELF usage. This survey of internet advertising in English in Thailand revealed that an increasing number of Thai internet users have relied on the English language to indicate modernity and their cosmopolitan personalities in contemporary Thai society.

Still concerning writing in English, Buripakdi (2012) studied perceptions of Thai professional writers towards Thai English. Through in-depth interviews, the researcher found that, for this group of participants, standard English, not Thai English, should be kept. This suggests that British and American English is still firmly regarded as "correct, implying that in Thai society, no other varieties of English other than British and American ones are held in high regards.

Ploywattanawong and Trakulkasemsuk (2014) explored attitudes of Thai graduates toward English as a Lingua Franca of ASEAN, focusing on the acceptability and understandability of those varieties of English found in ASEAN. The participants found “... deviated ASEAN ELF grammatical features ...” (p. 141) bearably acceptable and sufficiently understandable and that although certain respondents might have found some grammatical features incorrect, those features did not negatively affect mutually beneficial communication.

On a more literary focus, Watkhaolarm (2005) analyzed literary genre of Two Thai authors writing in English. Their writing is an example of contact literature, one written in English by non-native English authors whose English is nevertheless is considered "functionally" native-like. It was reported that many writing processes were involved in the creation of the novels studied, namely transfer of religious, cultural and social elements, translation, and lexical borrowing. The researcher concluded by predicting that Thai English (Thainess in English) is likely to develop in Thai society.

Focusing somewhat narrowly on a linguistic phenomenon called code-mixing, Sanprasert Snodin (2014) investigated the use of English names and code-mixing in Thai mass media, a significant arena for the use of English in everyday life. The most important finding reported is that Thai people have now become accustomed to the use of English for intranational communication, which corroborates a World Englihes argument that English or ELF is going to be increasingly used by and for people of the same nationality, the so-called intra-communication.

Snodin and Young (2015) investigated perceptions and attitudes of Thais toward native-speaker varieties of English. The study zeroed in on the following aspects: which varieties of English the respondents (Thai university students) thought they were using, which they saw as their target model and their general attitudes toward the varieties of Inner Circle Englishes such as American English, British English, Canadian English, Australian English and New Zealand English. The authors found that American English was most favored generally, but when it comes to desired accents, both British and American accents were equally preferred. One other significant result reported is that Australian English is not quite desirable among this group of respondents. Basically, the study corroborated other studies that American English is all the rage now.

The selected studies discussed above point to a key argument regarding World Englishes that English is being used increasingly in Thai society, although Thai English may not be used as widespread as Singaporean English or Indian English because there is no clear Thai English speech or discourse community to serve as a platform. This focused review of the literature implies that research should be conducted about World Englishes and local users of the language. Findings to be reported might shed light on the extent to which World Englishes will play a role in Thai society, especially in the domain of higher education, which is becoming more and more "international" in nature. In addition, the ASEAN community and its imminent Asean Economic Community (AEC) necessitate research into the perceptions and attitudes of Thais, especially those who are going to be actively involved in the use of English both intra- and internationally. As Snodin and Young (2015) aptly argue, such research might lead to a better realization of language policy and practice in Thai society as well as serve as a stepping stone for further analysis of the role of English in today's increasingly globalized world.

\section{Method}

\subsection{Participants}

The respondents were students enrolled in three universities in Bangkok, Thailand, majoring in diverse fields of 
study e.g., logistics, business administration, law, human resource development, economics, tourism management, language and communication, food and nutrition, engineering and food science. Quite a number of these $(\mathrm{N}=101)$ have never been abroad with only three respondents spending 8 months in English-speaking countries. The rest had been to other non-English speaking countries.

\subsection{Data Collection}

A set of questionnaires was distributed to Thai university students $(N=198)$ enrolled in three universities in Bangkok. However, the 158 completed questionnaire were returned. The questionnaire consisted of two parts. Part I was concerned with basic information about the participants. Part II focused on various aspects of World Englishes as follow: The inner, outer and expanding circles English (items 1 - 6), the concept of standard English (items 7 - 10), the ownership of English (items 11 - 13), "Thai English" (items, 14, 25, 30, 31 and 32), sources of a variety of English (items 15 - 22), testing (items 23 - 24), the role of native- vs. non-native English speaking teachers (items 26 and 27), others (items 28, 29).

\subsection{Data Analysis}

The responses to the questionnaire were analyzed and reported following the categorization of the 32 items included in the questionnaire so as to give a general impression of the answer patterns; subsequently, responses to each of the 32 items were presented via a pie chart to make it more concrete to the reader. This was followed by a discussion of the results.

\section{Findings and Discussion}

\subsection{Questionnaire findings}

Table 1. Patterns of responses concerning Thai university students' understanding of WEs based on the categorizations above $(\mathrm{n}=158)$. $\mathrm{SA}=$ strongly agree; $\mathrm{A}=$ agree; $\mathrm{D}=$ disagree; $\mathrm{SD}=$ strongly disagree; $\mathrm{N} / \mathrm{A}=$ no answer; $\mathrm{n}=$ total number of responses

\begin{tabular}{lllllll}
\hline Statement & (SA) & (A) & (D) & (SD) & (N/A) & (n) \\
\hline 1. Correct English is British English only & 14 & 43 & 62 & 12 & 27 & 158 \\
2. Correct English is American English only & 3 & 22 & 85 & 15 & 33 & 158 \\
3. Australian English should be counted as correct English & 10 & 55 & 42 & 10 & 41 & 158 \\
4. New Zealand English should be counted as correct English & 8 & 54 & 40 & 7 & 49 & 158 \\
5. Canadian English should be counted as correct English & 10 & 56 & 34 & 9 & 49 & 158 \\
6. Other varieties of English are incorrect & 7 & 29 & 56 & 18 & 48 & 158 \\
7. Correct English must have one standard & 33 & 75 & 30 & 3 & 17 & 158 \\
8. Standard English has the same rules of grammar & 35 & 87 & 20 & 3 & 13 & 158 \\
9. Standard English may differ in accents & 35 & 95 & 13 & 5 & 10 & 158 \\
10. Standard English is found only in writing & 6 & 61 & 56 & 18 & 17 & 158 \\
11. English belongs to those who speak it & 9 & 40 & 60 & 22 & 27 & 158 \\
12. British and Americans are owners of English & 10 & 48 & 48 & 26 & 26 & 158 \\
13. Singaporean, Indian and Philippine English are standard English & 10 & 63 & 28 & 16 & 38 & 158 \\
14. Thai English is just wrong English & 8 & 58 & 41 & 10 & 41 & 158 \\
15. You learned British or American English & 39 & 71 & 9 & 1 & 38 & 158 \\
16. WEs use same grammar but different vocab & 34 & 69 & 18 & 9 & 28 & 158 \\
17. WEs can be found in English novels & 22 & 83 & 20 & 3 & 30 & 158 \\
18. WEs can be found in print materials & 21 & 99 & 16 & 2 & 20 & 158 \\
19. WEs can be found in adverts & 23 & 100 & 16 & 3 & 10 & 158 \\
20. WEs can be found in SNSs & 28 & 96 & 20 & 4 & 10 & 158 \\
\hline
\end{tabular}


21. English at school must be British or Am Eng

22. Other types of English should be taught

23. English exam items should be Br or Am Eng

24. English exam items may have other Englishes

25. Thais should use Thai English for their identity

26. English teachers should be native speakers

27. Local teachers equally effective teachers

28. Some mistakes are fine if messages are clear

29. I choose to speak Br or Am English

30. Thai-accented English is embarrassing

31. Thais speaking with $\mathrm{Br}$ or Am accent is good

32. Heavy Thai-accented English is undesirable

\begin{tabular}{llllll}
34 & 71 & 23 & 6 & 24 & 158 \\
21 & 64 & 36 & 14 & 23 & 158 \\
31 & 63 & 29 & 8 & 27 & 158 \\
16 & 43 & 50 & 21 & 28 & 158 \\
13 & 29 & 53 & 34 & 29 & 158 \\
14 & 58 & 38 & 15 & 33 & 158 \\
31 & 77 & 19 & 4 & 27 & 158 \\
21 & 81 & 26 & 8 & 22 & 158 \\
42 & 74 & 17 & 6 & 19 & 158 \\
23 & 64 & 38 & 12 & 21 & 158 \\
23 & 82 & 30 & 6 & 17 & 158 \\
12 & 53 & 54 & 14 & 16 & 158 \\
\hline
\end{tabular}

Below is a detailed analysis of each of the 32 items reported in Table 1.

4.2 Focus on the Inner, Outer and Expanding Circles Englishes (Items 1 - 6)

Item 1: Correct English is British English only (-)

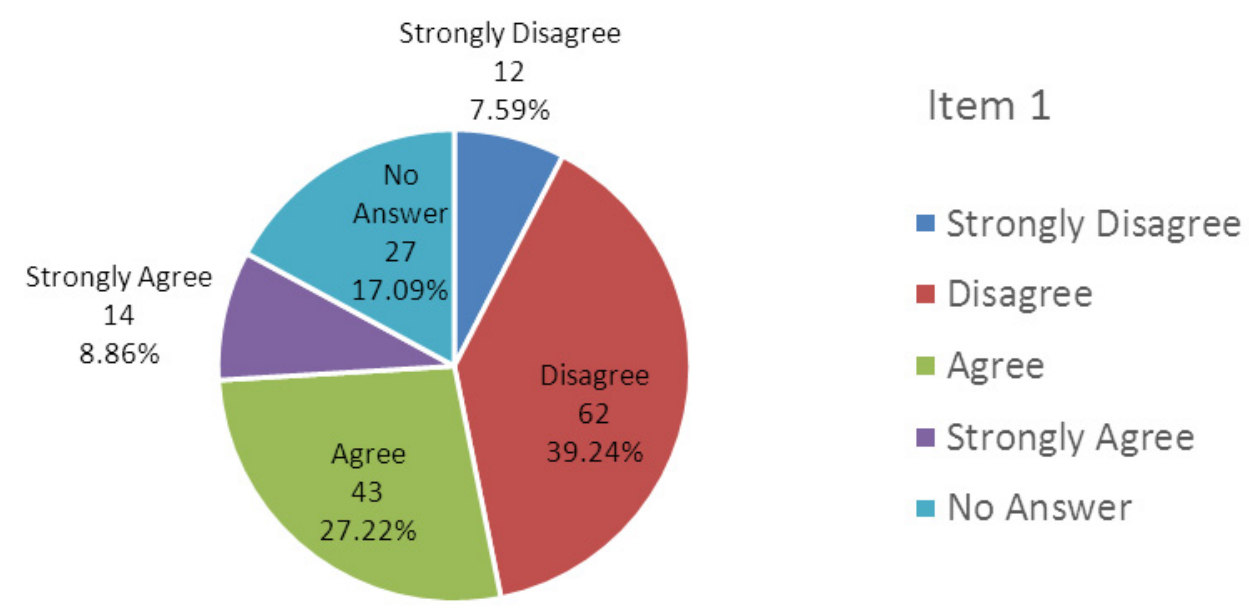

When asked whether they found British English the only correct English (item 1), almost 47\% either disagreed or strongly disagreed, leaving the rest agreeing to varying degrees and a good $17 \%$ did not answer. This may have been because the respondents were aware that there exists another competing variety, American English, that is considered equally correct English. When comparing this pattern of answering to that of item 29, which asked whether the respondents wanted to be able to speak either British or American English, I found that more than $73 \%$ of the respondents agreed or strongly agreed. This finding implies that the majority of the respondents considered the inner circle English e.g., British and American desirable. 
Item 2: Correct English is American English only (-)

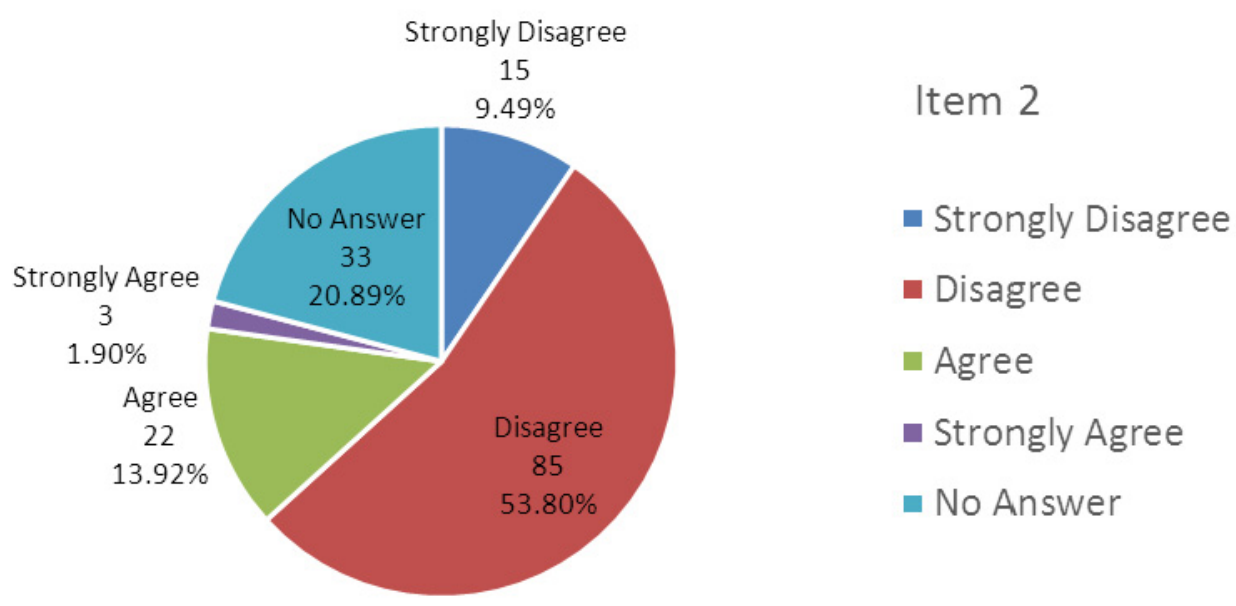

Almost $63 \%$ of the respondents either disagreed or strongly disagreed that only American English was correct English. This is consistent with the findings of item 1 above. This might be construed as a reflection of the legacy of British English popularity when Thailand mandated that (British) English be a school subject for the mass beginning in 1921 (Baker, 2009). That is, compared to British English, American English, to a no small number of Thais, might take a second rank in terms of "correctness."

Item 3: Australian English should be counted as correct English ( + )

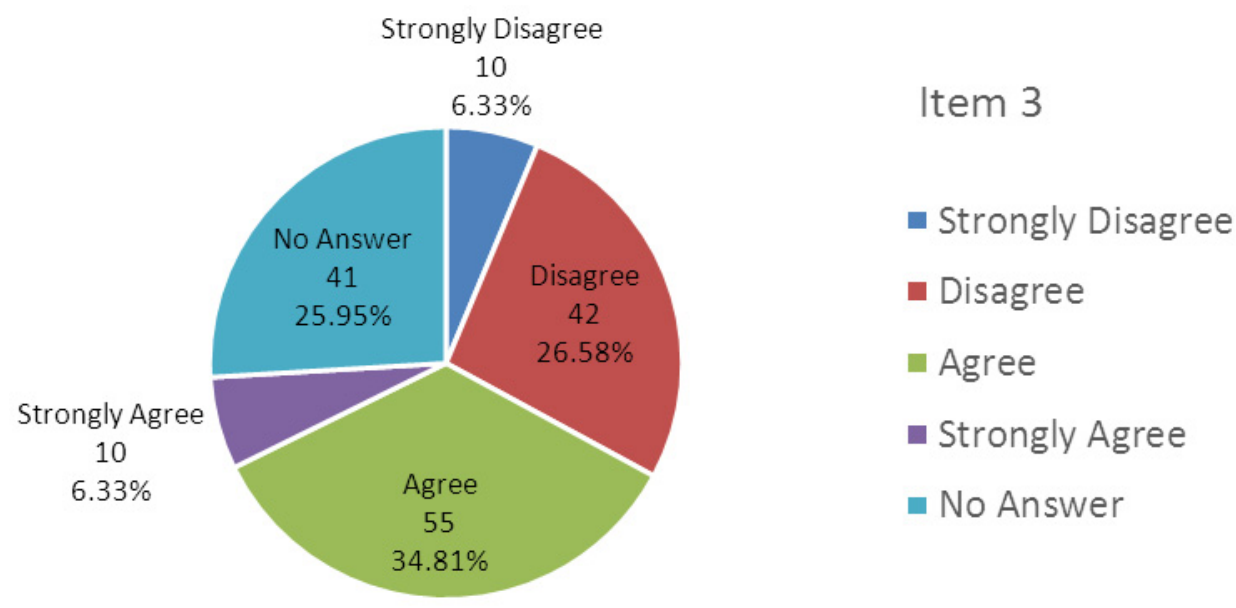

When it comes to whether Australian English should be correct English (item 3), approximately $41 \%$ either agreed or strongly agreed. In addition, a little more than a quarter of the respondents could not decide regarding this item. This pattern of responding was also found in item 5 below. 
Item 4: New Zealand English should be counted as correct English (+)

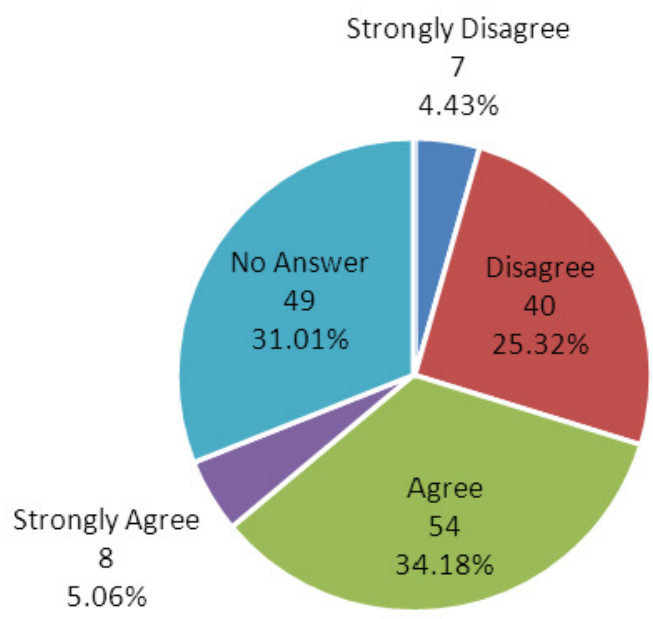

\section{Item 4}

- Strongly Disagree

- Disagree

- Agree

- Strongly Agree

- No Answer

The pattern of responses showed that $62 \%$ believed New Zealand English is correct English, and it should be noted that $31 \%$ did not know or were not sure about New Zealand English being correct with about 32\% disagreeing.

Item 5: Canadian English should be counted as correct English (+)

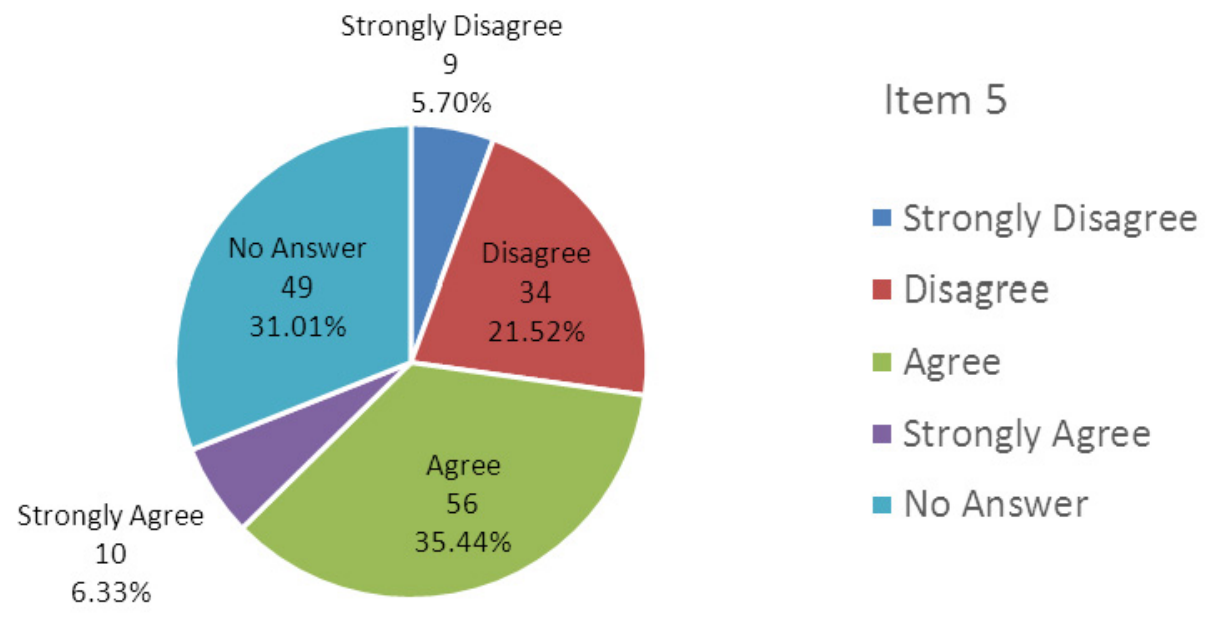

Like Australian English, Canadian English received approximately 41\% of either agreeing or strongly agreeing, thus resulting in 31\% giving no answer like in the case of Australian English. This might have been because the respondents were not familiar with both types of English, albeit considered standard English in their own right. 
Item 6: Varieties of English other than the ones mentioned in items 1-5 above are incorrect (-)

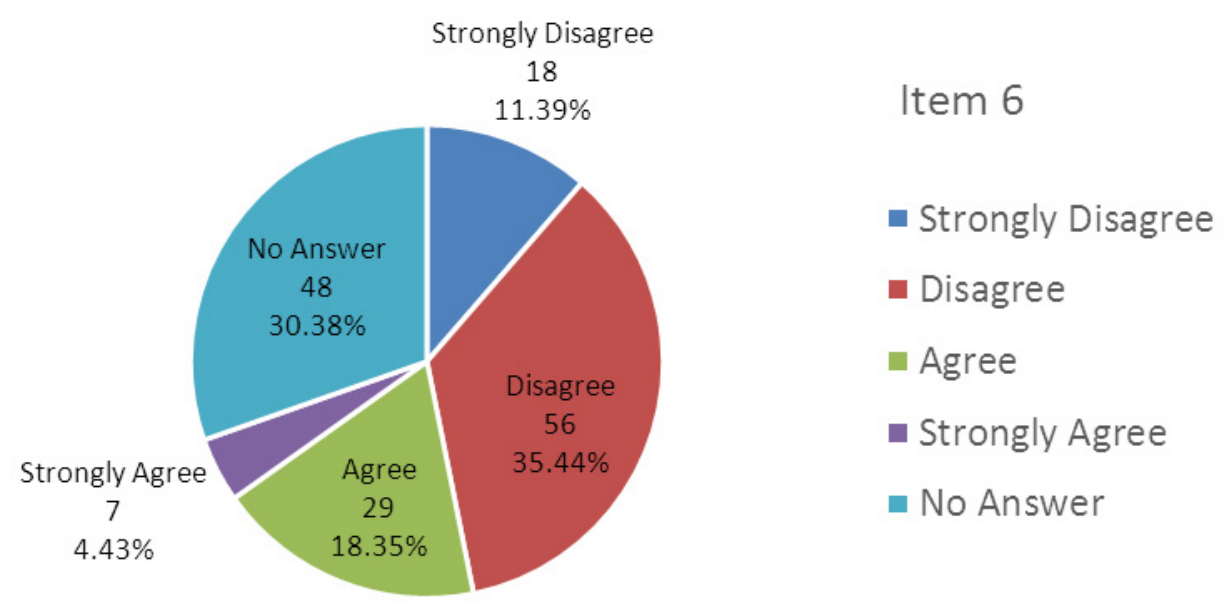

The patterns of response to this item revealed that almost half of the respondents $(46 \%)$ disagreed with the item and that $30 \%$ did not answer. This means that the majority of the respondents may have been aware that other varieties of English existed in addition to the inner circle English, although they did not know exactly what those varieties were.

4.3 Focus on the Concept of Standard English (items 7-10)

Item 7: Correct English must have one single standard. (-)

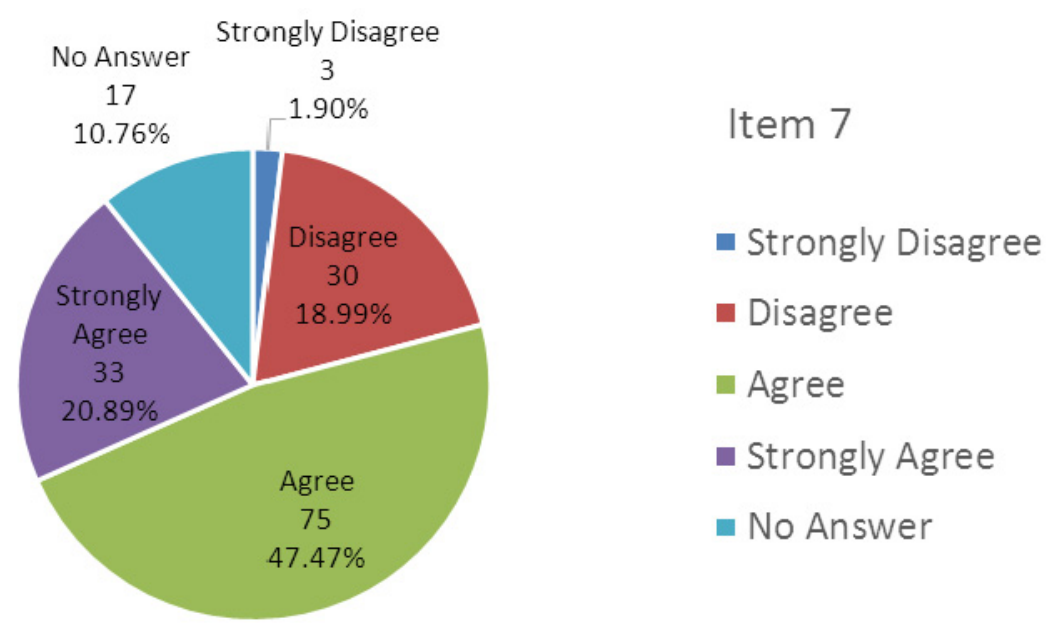

An overwhelming majority (68\%) either agreed or strongly agreed with this item, suggesting that the notion of standard is tied in closely with the English language and its use. Merely $20 \%$ either disagreed or strongly disagreed whereas a meager $11 \%$ did not answer. 
Item 8: Standard English must use the same grammar rules. (-)

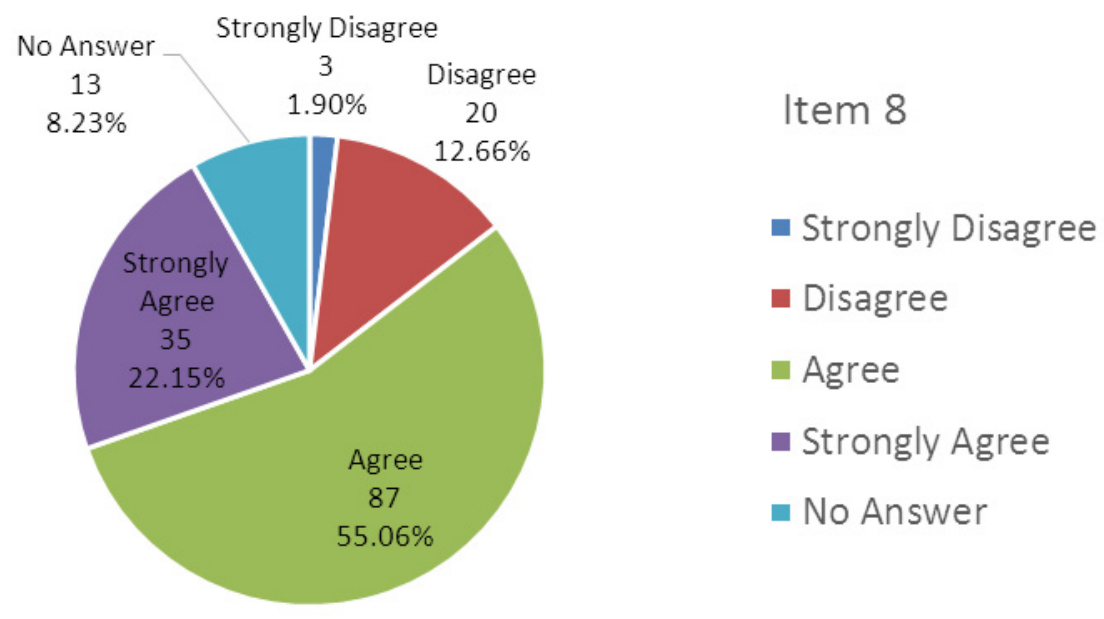

Similar to the findings reported in item 7, the majority of the respondents (77\%) believed that grammar rules should be the same for standard English, suggesting that grammar rules and the notion of standard must go hand in hand, although they did not necessarily know what the same grammar rules entail.

Item 9: Standard English may have different accents and pronunciations. $(+)$

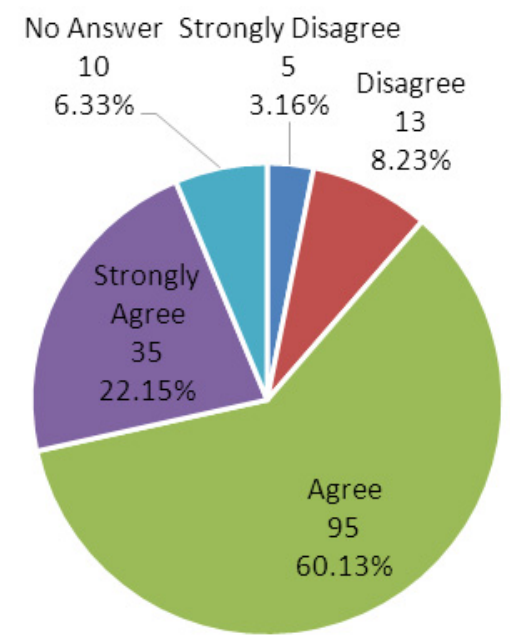

\section{Item 9}

- Strongly Disagree

- Disagree

- Agree

- Strongly Agree

- No Answer

$72 \%$ of the respondents concurred that different accents and pronunciations were to be expected in standard English; they might have relied on their familiarity with differences that do exist in accents and pronunciations found in British and American English, let alone other varieties. 
Item 10: Correctness and standard of English must be gauged through written English. $(+)$

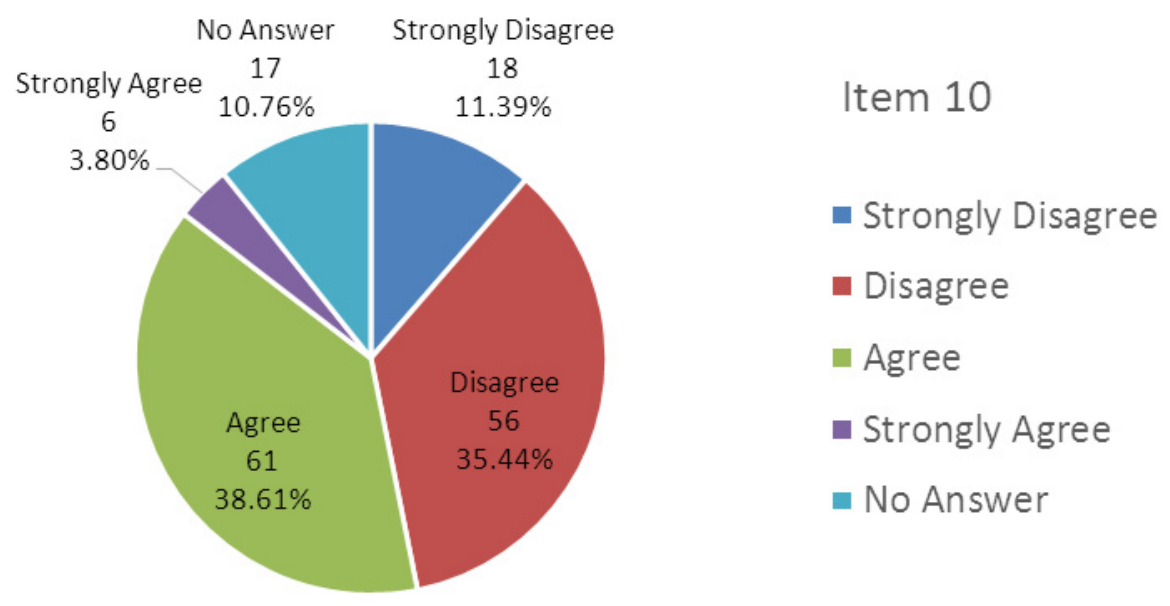

Slightly more than $46 \%$ either disagreed or strongly disagreed with this item whereas $42 \%$ either agreed or strongly agreed. This suggests that the respondents may have felt ambivalent whether written English should be the only means against which to measure correct and standard English.

4.4 Focus on the Ownership of English (items 11-13)

Item 11: English belongs to just about anyone who can speak it. $(+)$

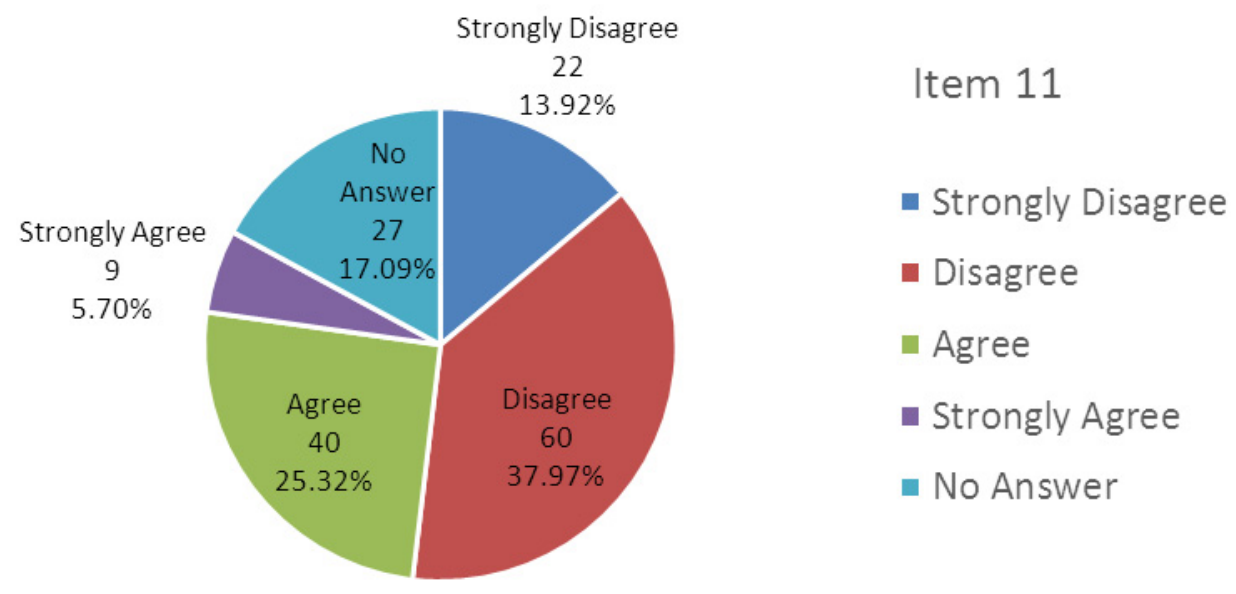

\begin{abstract}
About half of the respondents (51\%) either disagreed or strongly disagreed with this item, which might as well suggest that they still held on to the traditional concept of owners of English that it belongs to those in the inner circle countries, especially the U.K. and U.S.A. Additionally, a scant 5.7\% strongly agreed, whereas $17.09 \%$ gave no answer. This response pattern appeared to support the argument that ownership of such a global language strongly adheres to the inner circles.
\end{abstract}


Item 12: Only the English and Americans are rightful owners of English. (-)

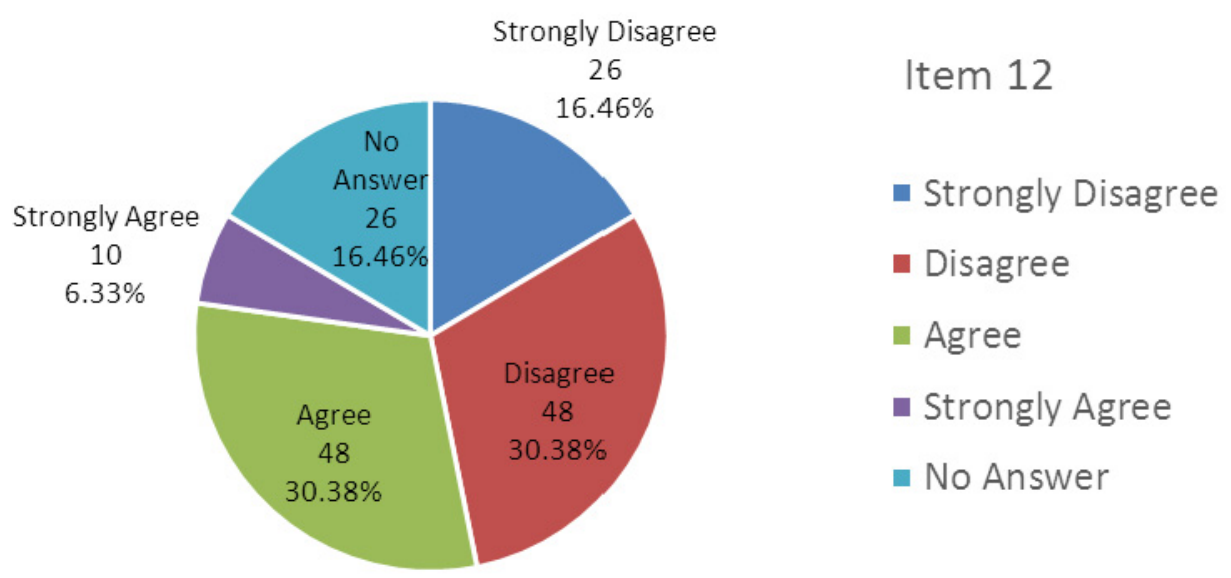

The respondents were equally divided between agreeing and disagreeing with $30.38 \%$ each whereas $16.46 \%$ did not answer and strongly disagreed, respectively. These findings revealed that the respondents might have found it hard to either agree or disagree, for the item involved an idea that they might not have thought before. Coupled with this is the fact that they might not have been familiar with WEs as an academic, sociolinguistic and political concept.

Item 13: Singaporean English, Indian English and Philippine English may be standard English. $\left(^{+}\right)$

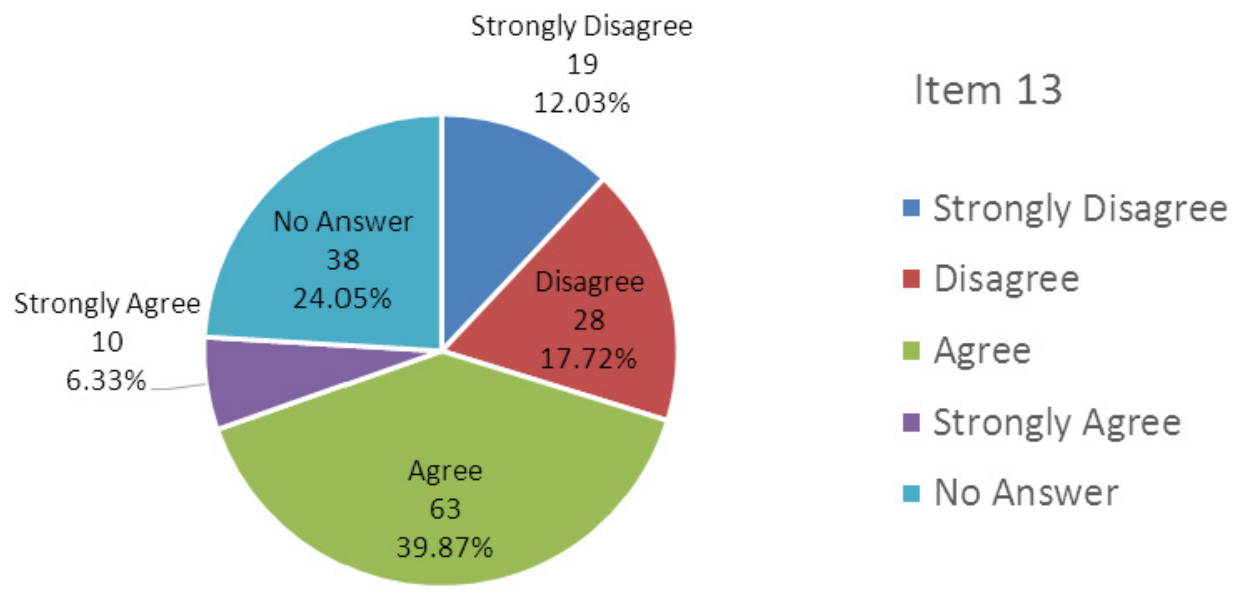

Almost half of the respondents (46\%) either agreed or strongly agreed with the item whereas $24 \%$ did not answer. This percentage appeared to suggest that the respondents were ambivalent as to whether those varieties of English should be considered standard on par with the inner circles English. 
4.5 Focus on the Concept of Thai English (items14, 25, 30, 31 and 32)

Item 14: Unlike Singaporean, Indian and Philippine English, Thai English is an individual idiosyncrasy. $(+)$

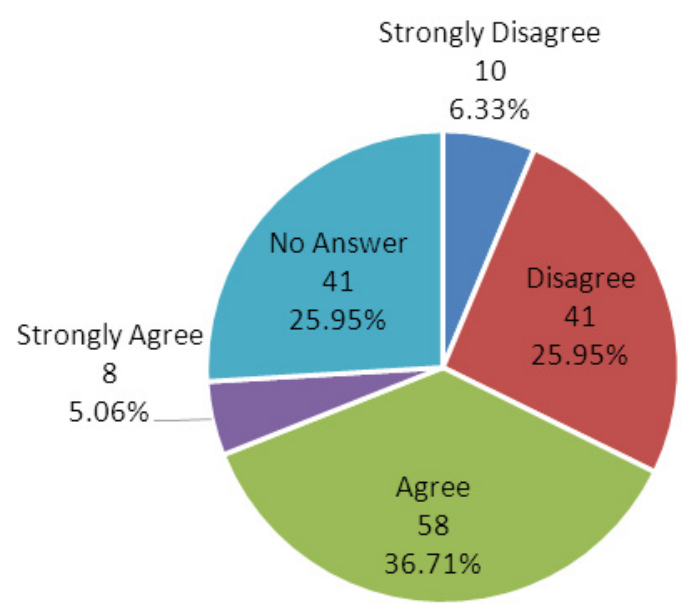

Item 14

- Strongly Disagree

- Disagree

- Agree

- Strongly Agree

- No Answer

About $42 \%$ of the respondents believed that Thai English did not have the same status as Singaporean, Indian and Philippine English and $25.95 \%$ could not answer. This means that the respondents were not quite certain whether Thai English exists as a variety of English.

Item 25: Thais should use Thai English to show their Thai identity. (+)

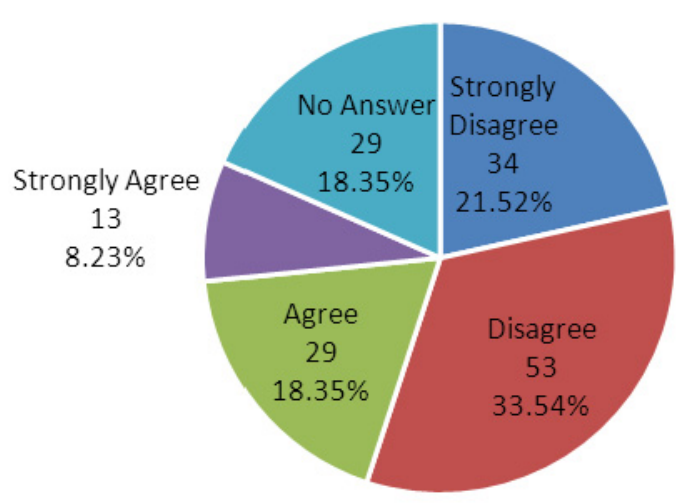

\section{Item 25}

- Strongly Disagree

- Disagree

Agree

- Strongly Agree

- No Answer

The pattern of response in this item clearly indicated that the respondents $(55 \%)$ disagreed with this item whereas only 26\% agreed. Thai English still doesn't have a place to be considered a variety of English in its own right; at least the respondents did not seem to favor it. 
Item 30: Speaking English with the Thai accent is embarrassing. (-)

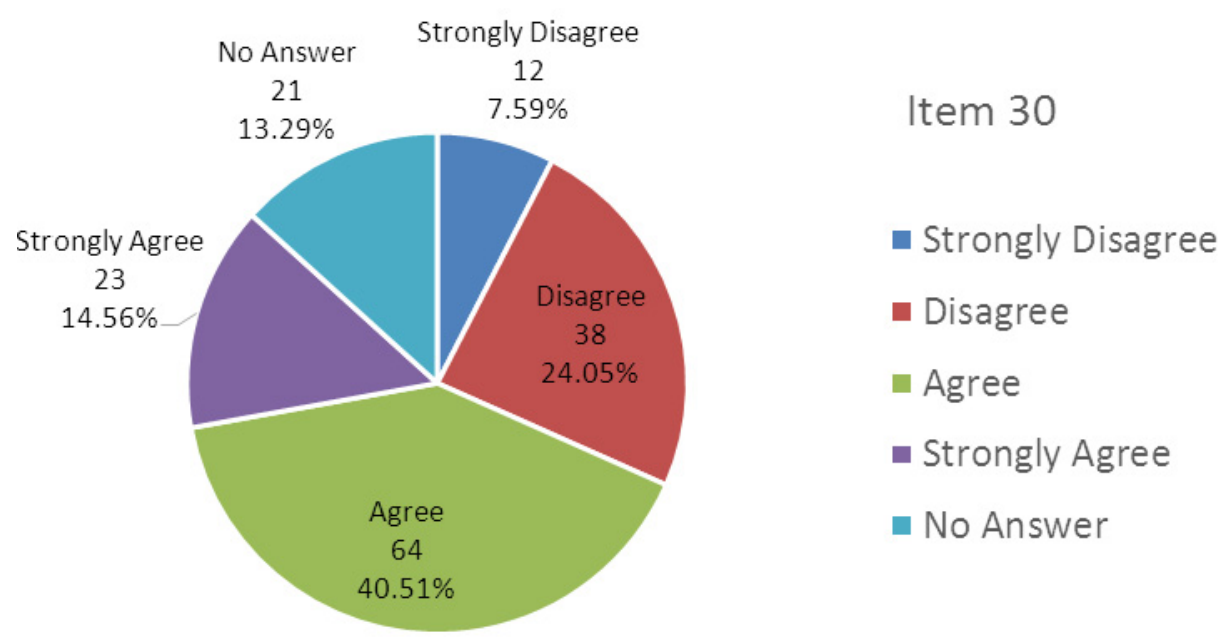

Approximately 55\% agreed with the item. Like the pattern of responses in item 29, the respondents seemed to have found the Thai accent as nonstandard.

Item 31: Any Thais who speak with the British or American accent is highly revered. (-)

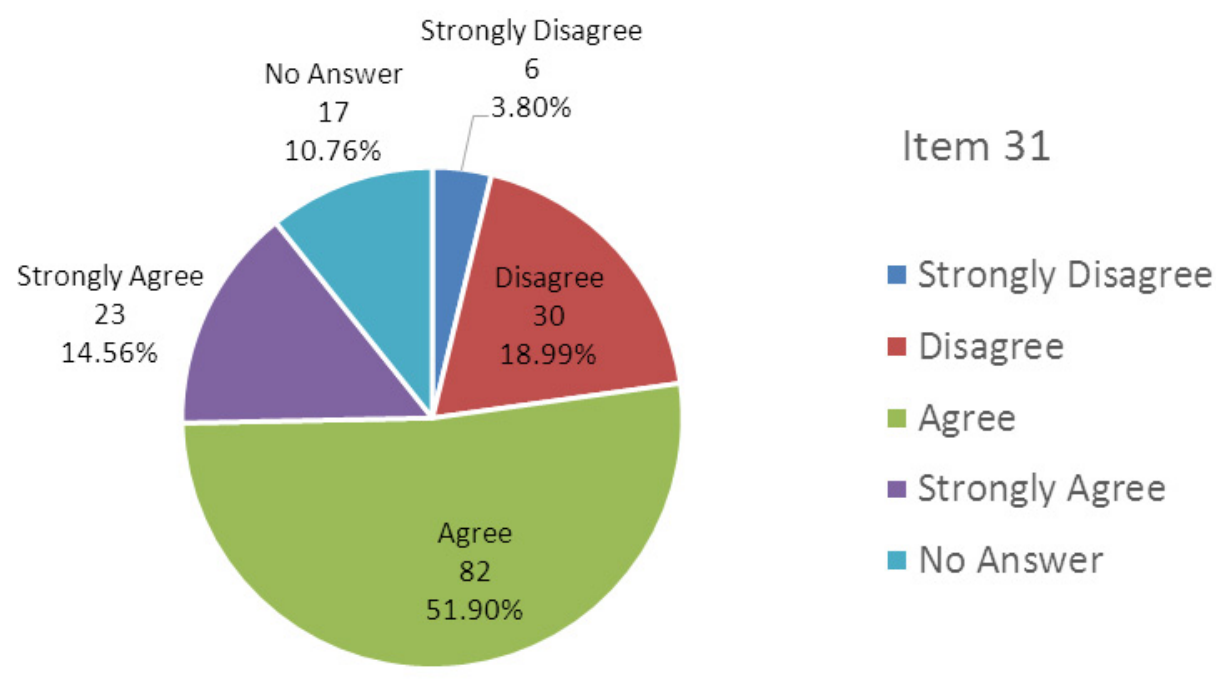

About $66 \%$ agreed whereas only $25 \%$ disagreed, suggesting that the respondents imbued the inner circle accents with high value. The findings here corroborated those reported in item 30 . 
Item 32: Any Thais speaking English with the heavy Thai accent is not good. (-)

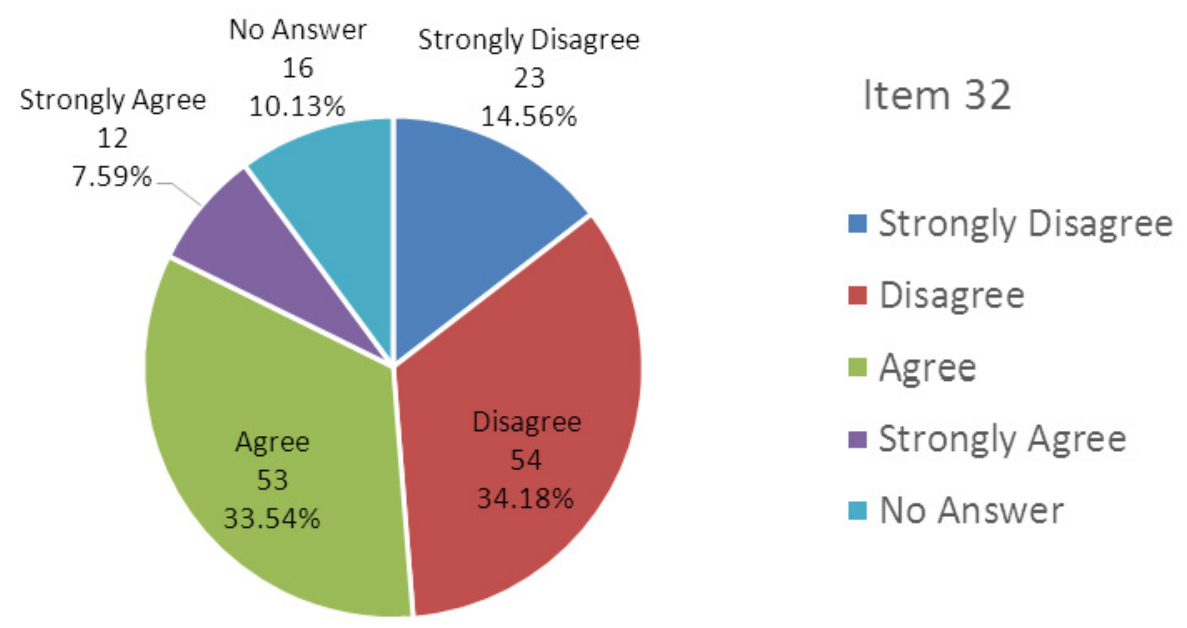

The respondents seemed to have been torn between agreeing (33.54\%) and disagreeing (34.18\%). Compared to the findings in the items above, the findings here suggest that the respondents were not sure whether the Thai accent would devalue their ability or perhaps they did not associate Thai-accented English with one's ability.

4.6 Focus on Potential Sources of a Variety of English (items 15 -22)

Item 15: As a student, you learn either British or American English at school. (-)

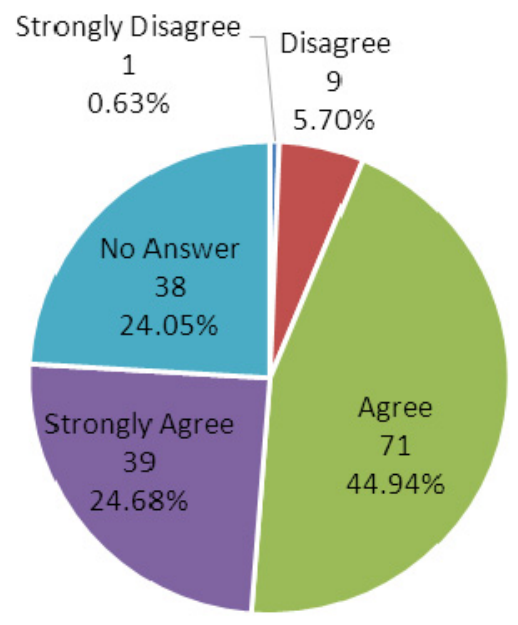

\section{Item 15}

- Strongly Disagree

- Disagree

- Agree

- Strongly Agree

- No Answer

Almost 70\% believed they learned either British or American English whereas 24\% did not answer, leaving only $6 \%$ disagreeing. This suggests that most of the respondents realized they had learned the inner circle English rather than Thai English. 
Item 16: World Englishes uses the same grammar rules but different vocabulary items. ${ }^{(+)}$

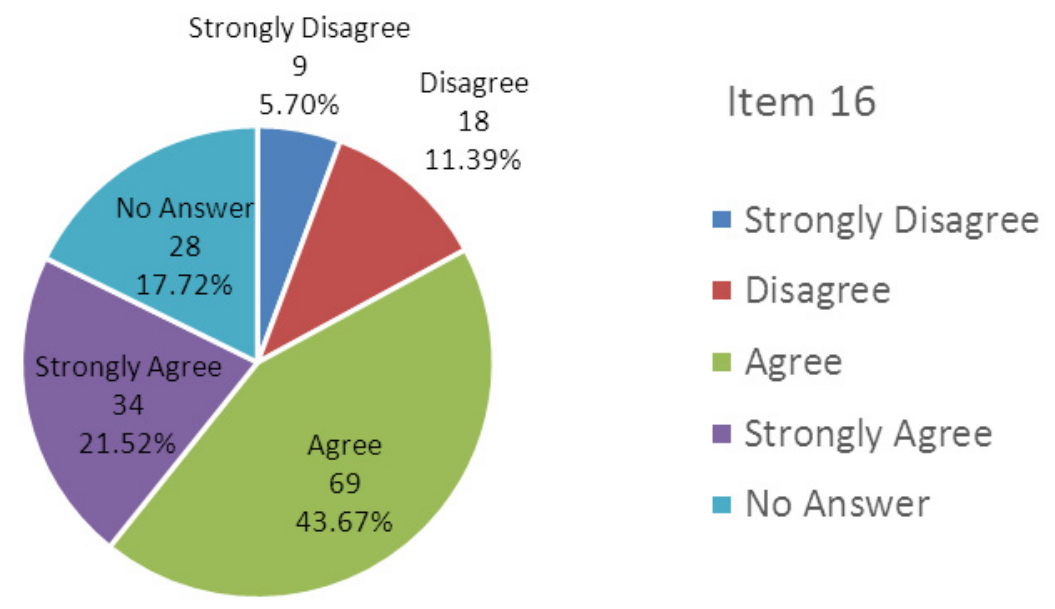

Approximately $65 \%$ agreed or strongly agreed that the differences should lie in vocabulary use rather than grammar. The percentage of no answer was almost $18 \%$, suggesting that some respondents were not certain about this point.

Item 17: World Englishes can be found in English novels. $(+)$

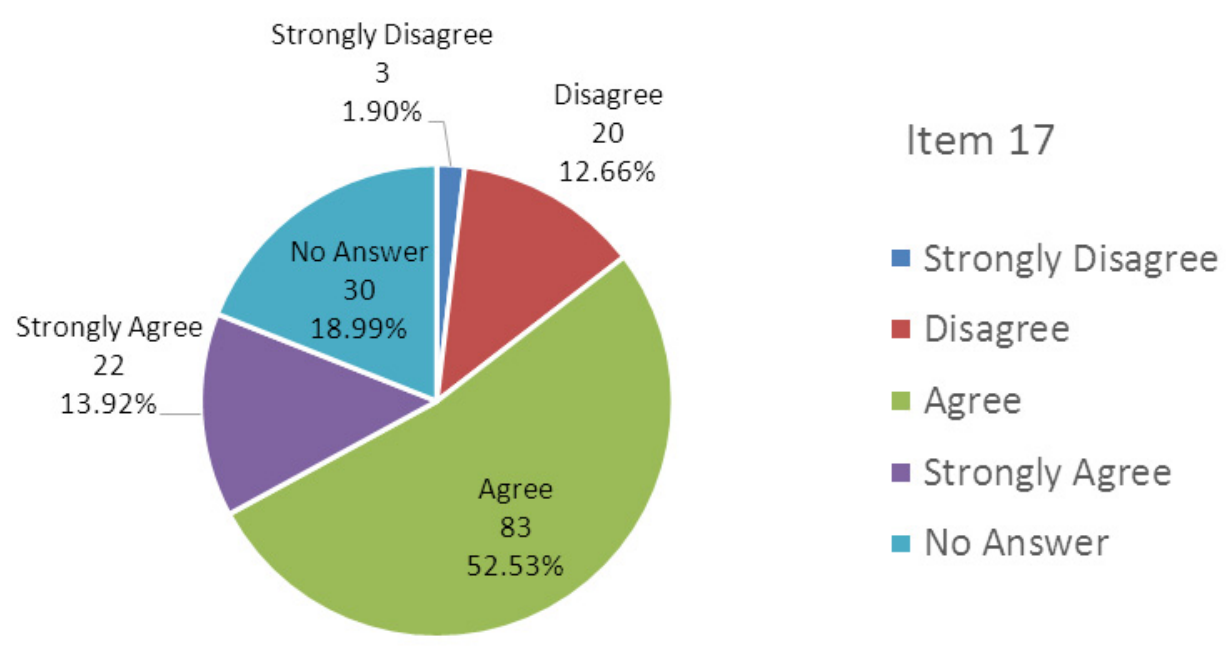

Approximately $66 \%$ either agreed or strongly agreed perhaps because they realized that novels were the source where indigenous vocabulary items may be found, reflecting the local identity. But the percentage of no answer $(18.99 \%)$ should not be disregarded because it reveals that certain respondents were not aware of this element. 
Item 18: World Englishes can be found in print materials. $(+)$

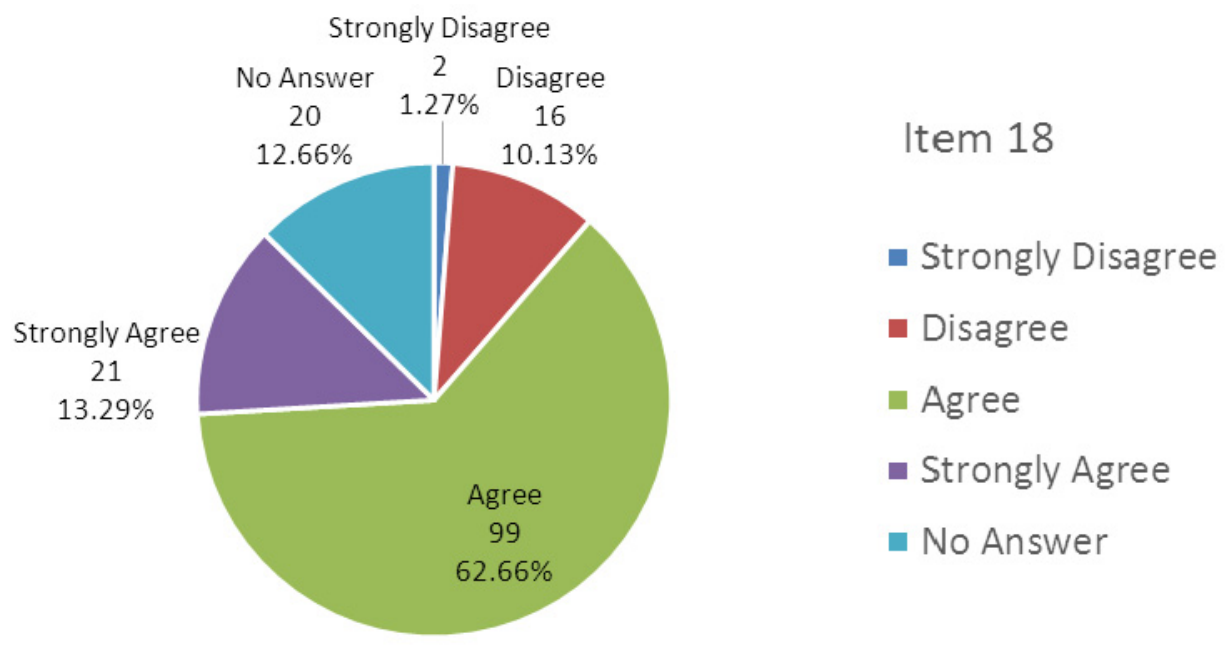

More than $75 \%$ of the respondents either agreed or strongly agreed with this item, implying that they believed print materials such as newspapers, brochures and magazines written in English should be the places where they could find examples of WEs. It can be inferred that print materials are general enough for varieties of English to be found.

Item 19: World Englishes can be found in advertisements. $(+)$

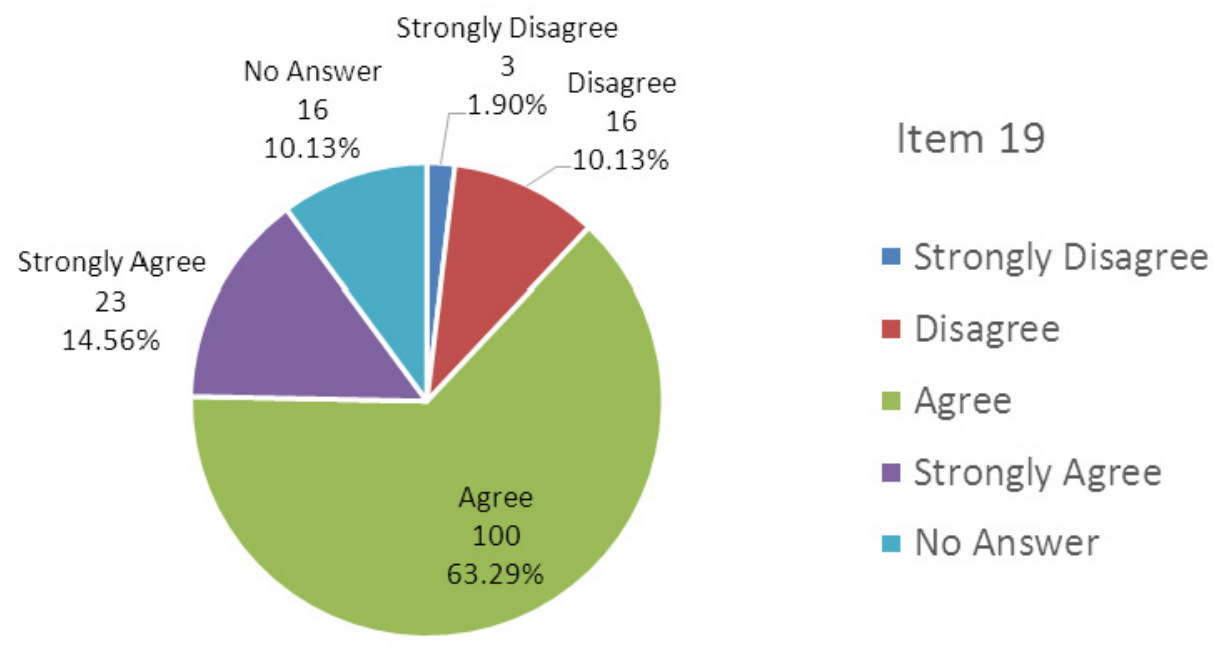

Almost $78 \%$ of the respondents agreed with the item, which is quite predictable because advertisements are oftentimes a platform to display examples of WEs. After all, one major characteristic of WEs is its creativity, one of the key ingredients of advertisements. 
Item 20: World Englishes can be found in social network sites. $(+)$

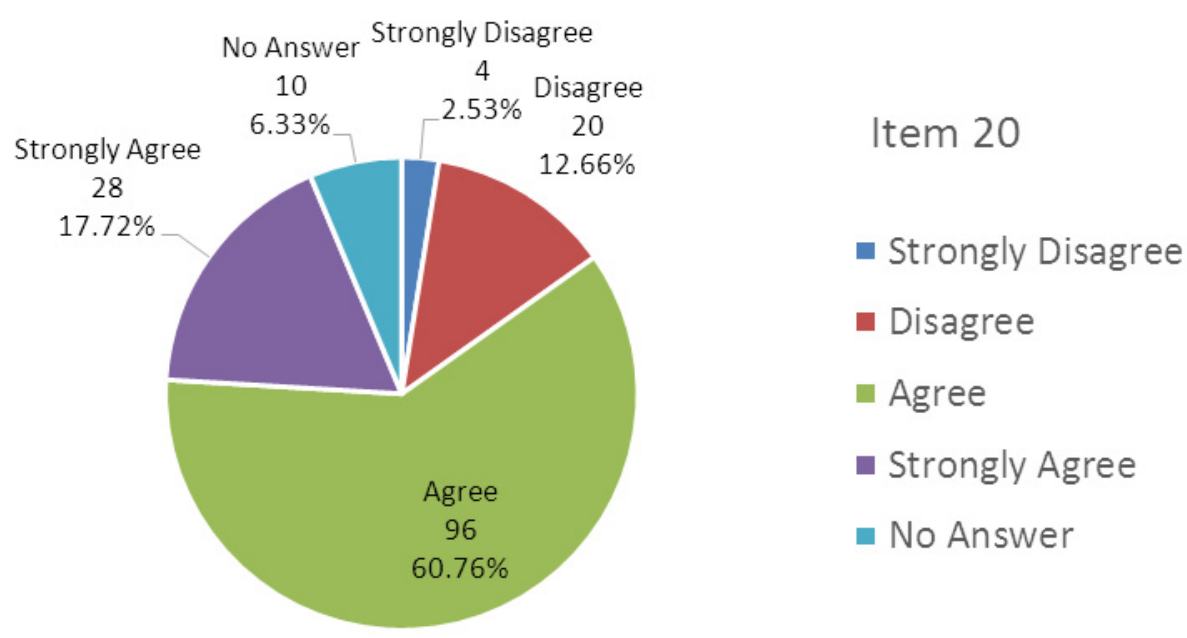

Like the findings of item 19, the response pattern of this item reveals that the majority of the respondents (78\%) found that social network sites are the places for WEs. Similar to the role of advertisements, social network sites are imbued with considerable creativity in language use. In addition, the respondents are best characterized as belonging to the digital generation because they grew up with computers and whatnot.

Item 21: English taught at school must be either British or American English. (-)

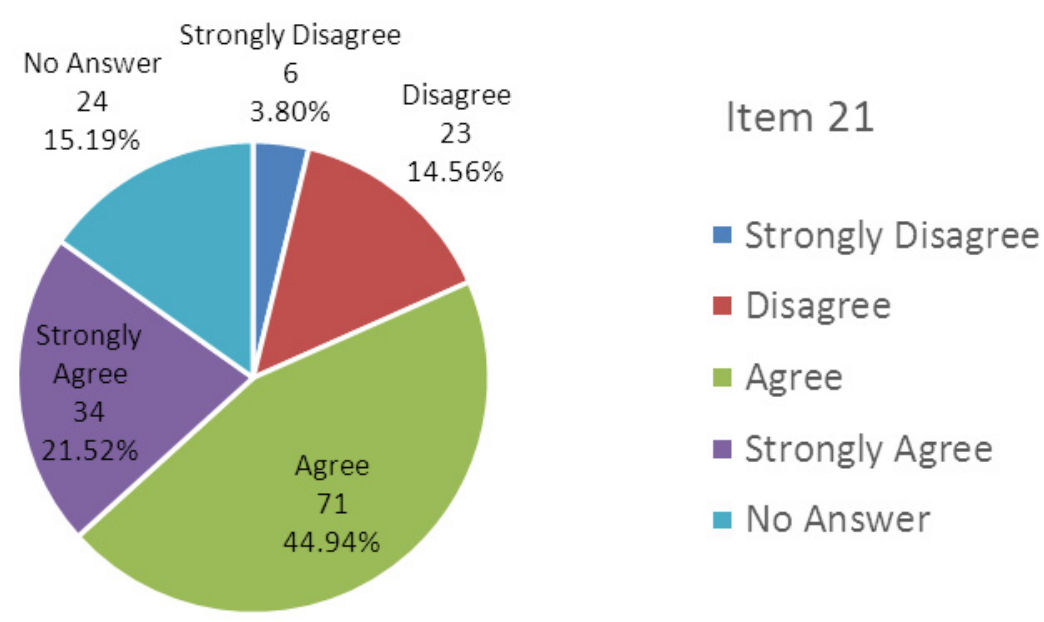

The response pattern $(66 \%)$ in this item revealed that many respondents still clung to the traditional concept that English to be taught at school should be either of the two kinds mentioned. 
Item 22: It may be interesting to teach varieties of English other than British or American English. $\left(^{+}\right)$

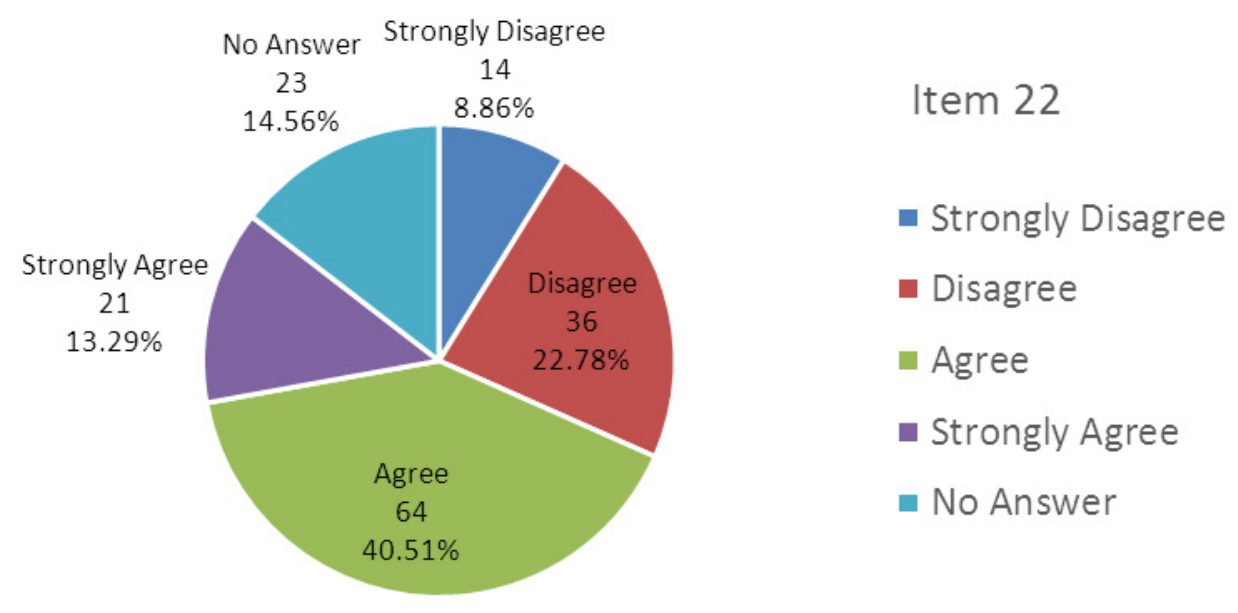

Approximately $53 \%$ of the respondents found this item acceptable, suggesting that they might have realized that it wouldn't hurt if other varieties of English would be introduced to them. But it should be noted that the percentage of no answer was also of interest, implying that some of the respondents had not yet become cognizant of WEs.

4.7 Focus on the Issue of English Language Testing (items 23 - 24)

Item 23: English exam items should be only British or American English. (-)

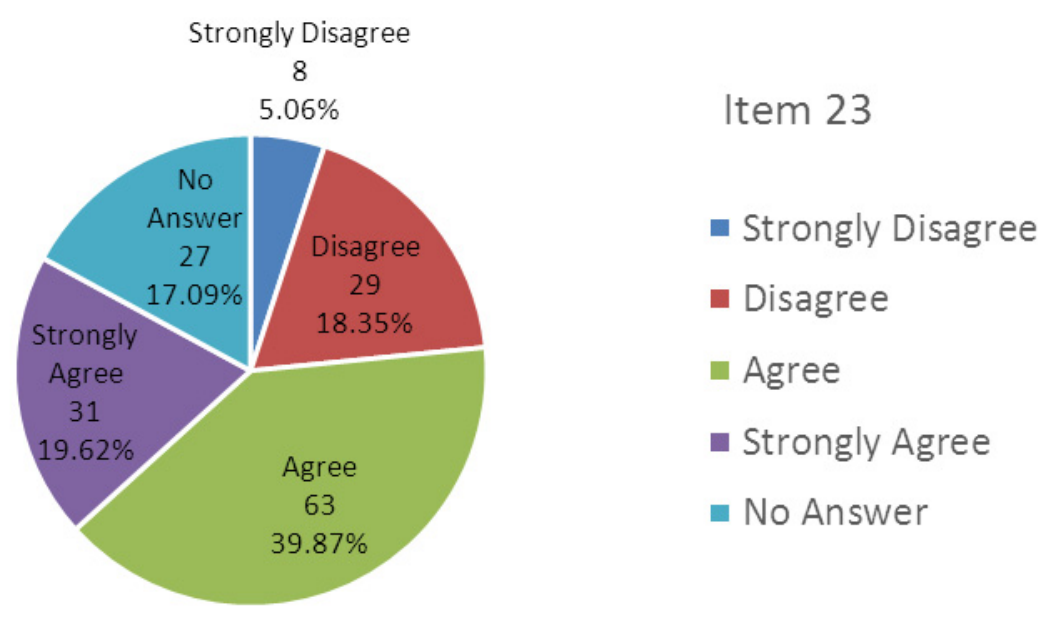

The response pattern revealed that more than $58 \%$ of the respondents either agreed or strongly agreed, although approximately $23 \%$ disagreed. This suggests that the respondents might have been ambivalent. The nature of this response pattern is clearly contrasted with that of the next item below. 
Item 24: English exam items may contain other varieties of English. $(+)$

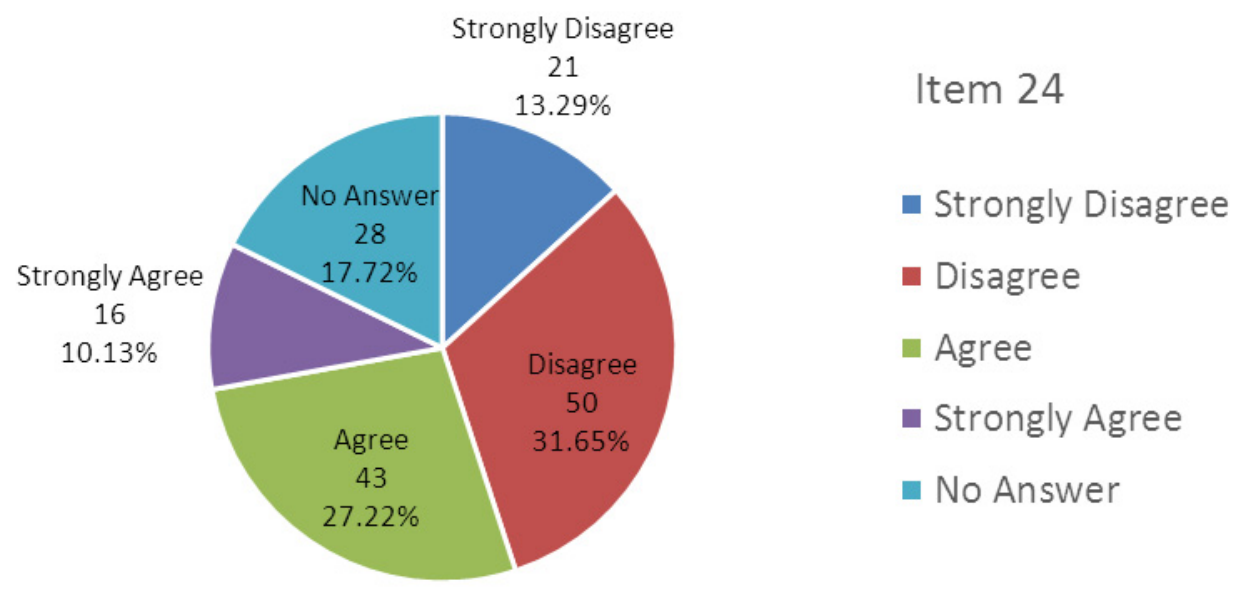

Unlike the responses in item 23, the response here suggests that the respondents were somewhat reluctant to include other varieties of English in English exams. This was reflected in the higher percentage for the disagreement category (45\%) as opposed to the agreement category (37\%).

4.8 Focus on the Role of Native and Non-native English Speaking Teachers (items 26 and 27)

Item 26: English teachers should be English native-speaking teachers only. (-)

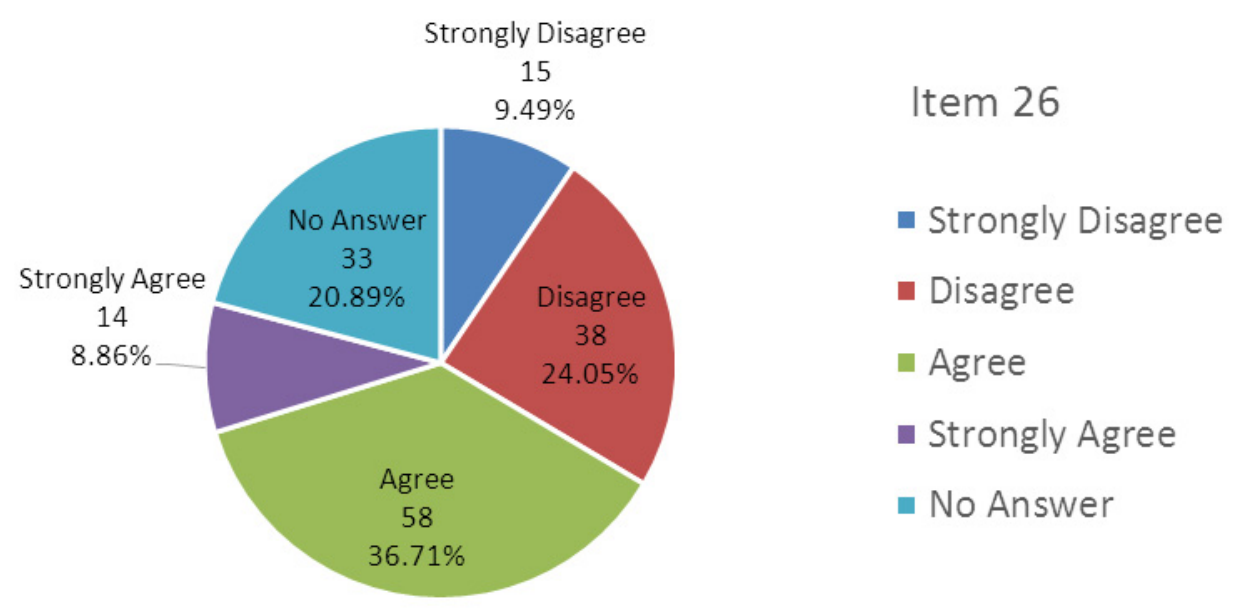

Almost $46 \%$ of the respondents agreed with this item whereas 33\% disagreed, leaving almost $21 \%$ not answering. The ambivalent attitude shown here toward native or non-native teachers may not be answered as having sweeping generalizations. 
Item 27: Local teachers of English should be considered equally effective. $(+)$

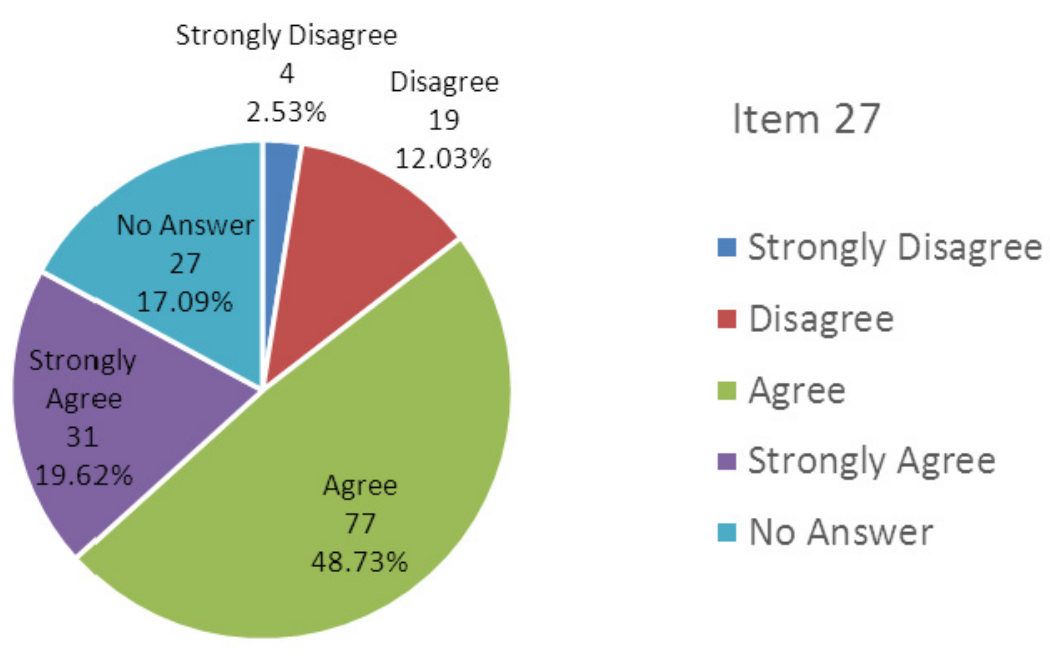

The response pattern for this item reaffirmed that the majority of the respondents (69\%) found that local teachers can teach effectively. This finding suggested that the ambivalent attitude that they had about English native-speaking teachers (item 26) may be rational.

4.9 Focus on Miscellaneous Aspects of WEs (items 28 - 29)

Item 28: English messages with sporadic grammatical mistakes are fine as long as the message can be understood. $(+)$

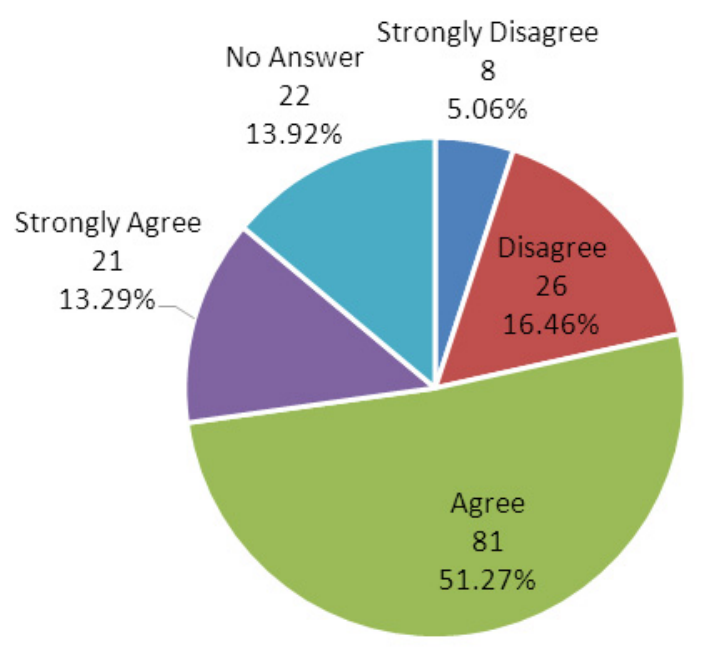

Item 28

- Strongly Disagree

- Disagree

Agree

- Strongly Agree

- No Answer

About $64 \%$ agreed with this item, suggesting that the respondents thought about English as a means of communication. Grammatical accuracy should be secondary in importance. Thus the notion of correct English has been somewhat relaxed. 
Item 29: If I can choose, I will speak either British or American English. (-)

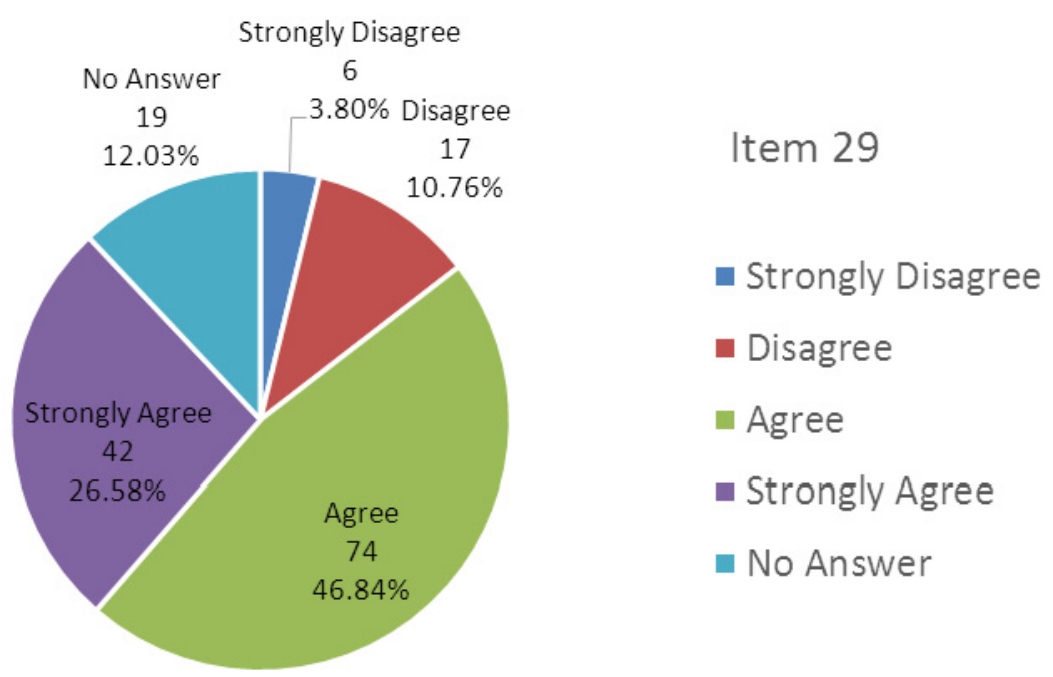

More than $72 \%$ agreed that they would like to be able to speak either British or American English. The pattern of responses clearly indicates a strong tendency on the part of the respondents to rely on British or American English as standard in terms of speaking the language.

\section{Summary and Conclusion}

Overall, the patterns of all the responses suggest several key points regarding the participants' attitudes toward WEs. First, it appears that the majority of the respondents clung to a long-established belief that British and American English are "better" versions of English as compared to other varieties. Nevertheless, when asked whether other varieties of English are incorrect, almost half disagreed and 30\% did not answer. These two percentage points implied that the participants did not understand one of the main arguments of WEs--that no single standard English is touted. This finding was corroborated by the respondents' answers to Item7, which asked whether correct English must have one single standard, to which the majority (68\%) agreed. It can be, therefore, concluded the respondents followed the main definitions of standard English as suggested by Jenkins (2015) that "...refer specifically to British English [and] all Inner Circle Englishes" (p. 24). It should also be noted that the respondents found accent to be of importance when considering standard English. This is consistent with what Jenkins proposed that "the British general public associate the 'standard' with an RP accent' (Jenkins, 2015, p. 26).

Second, the respondents also found that grammar rules are crucial when considering standard English. This is in line with an argument that "the term Standard English refers to grammar and vocabulary (dialet)..." (Jenkins, 2015 , p. 24). Indeed, when it comes to "standard" use of grammar or accuracy, the majority found meaning conveyed is more important than grammatical accuracy. This seemingly paradoxical response pattern comes as no surprise because what the respondents desired (British or American English) is not necessarily the same as the issue of grammatical accuracy. However, almost equal numbers of respondents either agreed or disagreed whether written English should be the bearer for standard and correct English. This ambivalent attitude implied that written English should conform to the same rules, hence standard. Equally important is the response pattern of Item 16 that it is vocabulary items rather than grammar rules that should allow for differences found in WEs, thereby reaffirming the respondents' belief that grammar has to remain fixed but vocabulary is more flexible.

Third, the fact that more than half of the respondents found the issue of ownership of English of dubious quality suggests that, for this group of respondents, the ability to speak English may not have anything to do with owning the language itself. After all, for general Thais who live in a monolingual society and whose official language is central or Bangkok Thai, the idea of owning a foreign language such as English may not cross their minds due to the lack of its colonial history. In addition, unlike the response pattern of Item 12, which asked whether English and American people are rightful owners of English, the respondents were divided between agreeing and disagreeing, 
Fourth, the respondents' answers to Item 17, which asked about WEs in English novels, were of interest because the majority concurred that English novels should be where they can find examples of WEs. In fact, the same patterns of responses could be found in their answers to Items 18, 19 and 20, all of which focused on real materials where WEs can be found such as print materials, advertisements and social network sites. Although the respondents did not necessarily know that important dimensions of WEs are innovation, creativity and playfulness, they might have entertained the notion that WEs is English in practice which entails the real context of use rather than English that resides in a dictionary or grammar book.

Fifth, considering the pedagogical dimension of WEs, the respondents appeared to have oscillated between adhering to British or American English and embracing other varieties. For example, they agreed either the British or American model should be the only model to be taught to students, but at the same time they realized that other varieties should be given a chance. However, when it comes to English language testing, they strove toward British or American English. This implies that when the stake is high such as tests or exams, the traditional (insinuating standard) should be the only viable option. The respondents' oscillation between British or American English and other varieties pointed to the ambivalent understanding of WEs.

Furthermore, the respondents detested the idea that Thais should speak Thai English in order to reveal Thai identity. Although identity is of paramount concern in WEs, the respondents clearly stated that Thai English is undesirable. The fact that the term Thai English has a pejorative meaning reaffirms the point made earlier that Thai English is not on a par with other varieties of English, for it does not have a deeply-rooted status of being a language of intra-national communication like Indian English.

As far as the English teacher is concerned, the respondents found local teachers as effective as native ones. This response might be interpreted that the respondents may have paid more attention to how a teacher teaches rather than whether a teacher is a native or a non-native speaker of English. Certainly, the myth of native versus non-native English speaking teachers deserves further scrutiny.

Finally, the respondents were not hesitant to confirm that message understanding was more important than grammatical accuracy. While this kind of response might not necessarily indicate their understanding of WEs, it alluded to a position taken by the respondents that English, in their opinion, is for communication rather than for grammatical analysis, hence sporadic grammatical mistakes should be condoned.

The respondents' many strands of arguments revealed their ambivalent perceptions toward WEs; they averred the important role of English but they may not have been familiar with WEs, which is concerned with not just English but, more importantly, the political, sociolinguistic, educational, economic and intercultural dimensions of language use. Based on this line of reasoning, answers to RQ 1, which is about the respondents' perceptions towards WEs, were what one would anticipate. That is, most of the respondents still held on to the idea that English is either British or American English. While this is not problematic in itself, it runs against the WEs concepts of democracy and plurality rather than linguistic plurality as emerging norms.

As for RQ 2, which concerns the respondents' understanding of WEs, the responses indicated that most of the respondents did not clearly understand key concepts of WEs, namely standard English, the ownership of English, the roles of native-vs. non-native English speaking teachers. Despite this lack of understanding, it is premature to conclude that they did not accept WEs as desirable. Rather, several of their answers (Items 17, 18 and 19) revealed that they were slightly aware that WEs was to be found in real-life situations or contexts.

In closing, this study attempted to elucidate the perceptions of Thai university students towards WEs and the extent to which such perceptions revealed their understanding of WEs. Certainly, Thais still prize the English language as a desirable asset. In so doing, they uphold select varieties such as British and American.

\section{Implications for Teaching and Research}

In order to enable Thai EFL students to be familiar with WEs, teachers might consider using Thai literature that has been translated into English such as Four Reigns. In the novel, students will find examples of Thainess in English, and this might make them feel more at ease reading this kind of materials because of the content familiarity accorded.

In terms of listening instruction, it might be useful to incorporate other varieties of accents and pronunciation so as to make students aware of difference that exist in the real world. Some of the convenient resources are, for example, CNN broadcast where students will hear different accents of English that are nevertheless intelligible enough. While the implementation of testing may require "standard" American or British English, it does not 
hurt to expose students to other varieties so that they will become alert to this sociolinguistic reality.

In addition, future research might focus on Thainess in English and the role of English in Thai media, business, entertainment and everyday life. This is so because Thainess is a topic that reflects how Thais use English better than Thai English, although Watkhalarm (2005) argued that Thai English is in the process of developing. For Thai English, unlike Indian or Singaporean English, does not have a speech community to serve as a platform. Whenever Thai English is mentioned, it tends to refer to incomplete or inaccurate use of English at the individual level. My argument is that Thai English may be difficult, if not impossible, to take root in Thai society. Further, because many universities and schools in Thailand are now offering programs of study where English is a medium of instruction (EMI), research might be conducted focusing on such aspects of EMI in Thai educational settings as English as a lingua franca (ELF) pragmatics. ELF pragmatics might provide another viable avenue to explore sociolinguistic and discoursal characteristics of ELF pragmatics that capture the metamorphosis of English in real situations.

\section{References}

Baker, W. (2009). The cultures of English as a lingua franca. TESOL Quarterly, 43(4), 567-592.

Bennui, P., \& Hashim, A. (2014). Stylistic creativity in Thai English fiction. Asian Englishes, 16(2), 80-100. http://dx.doi.org/10.1080/13488678.2014.901002

Bolton, K. (2004). World Englishes. In A. Davies \& C. Elder (Eds.), The handbook of applied linguistics (pp. 369-396). Oxford, England: Blackwell. http://dx.doi.org/10.1111/j.1467-971X.2004.00337.x

Buripakdi, A. (2012). On professional writing: Thai writers' views on their English. International Journal of Applied Linguistics, 22(2), 245-264. http://dx.doi.org/10.1111/j.1473-4192.2012.00311.x

Chutisilp, P. (1984). A sociolinguistic study of an additional language: English in Thailand. Unpublished PhD dissertation. University of Illinois at Urbana-Champaign.

Glass, T. (2009). Why Thais write to other Thais in English. World Englishes, 28(4), 532-543. http://dx.doi.org/10.1111/j.1467-971X.2009.01610.x

Cogo, A. (2008). English as Lingua Franca: Form Follows Function. English Today, 24(3), 58-61. http://dx.doi.org/10.1017/S0266078408000308

Higgins, C. (2003). "Ownership" of English in the outer circle: An alternative to the NS-NNS dichotomy. TESOL Quarterly, 37(4), 615-644. http://dx.doi.org/10.2307/3588215

Jenkins, J. (2006). Current perspectives on teaching World Englishes and English as a lingua franca. TESOL Quarterly, 40(1), 157-181. http://dx.doi.org/10.2307/40264515

Jenkins, J. (2015). Global Englishes: A Resource Book for Students ( $3^{\text {rd }}$ edition). Routledge.

Kachru, B. (1990). World Englishes and applied linguistics. World Englishes, 9, 3-20. http://dx.doi.org/10.1111/j.1467-971X.1990.tb00683.x

Kachru, B. (1992). The Other Tongue. English Across Cultures ( $2^{\text {nd }}$ edn). Urbana, IL: University of Illinois Press.

Kirkpatrick, A. (2012). English in ASEAN: implications for regional multilingualism. Journal of Multilingual and Multicultural Development, 33(4), 331-344. http://dx.doi.org/10.1080/01434632.2012.661433

Kumaravadivelu, B. (2012). Individual identity, cultural globalization, and teaching English as an international language: The case for an epistemic break. In L. Alsagoff, S. L. Mckay, G. Hu, \& W. A. Renadya (Eds.), Principles and practices for teaching English as an international language. (pp. 9-27). New York, USA: Routledge.

Mahboob, A., \&Liang, J. (2014). Research and critiquing World Englishes. Asian Englishes, 16(2), 125-140. http://dx.doi.org/10.1080/13488678.2014.915625

Masavisut, N., Sukwiwat, M., \& Wongmontha, S. (1986). The power of the English language in Thai media. World Englishes, 5(2), 197-207. http://dx.doi.org/10.1111/j.1467-971X.1986.tb00726.x

Mondiano, M. (1999b). Standard English(s) and educational practices for the world's lingua franca. English Today, 15(4), 3-13. http://dx.doi.org/10.1017/S0266078400011196

Nelson, C. (2011). Narratives of classroom life: Changing conceptions of knowledge. TESOL Quarterly, 45(3), 
463-485. http://dx.doi.org/10.5054/tq.2011.256799

Nelson, M., \& Kern, R. (2012). Language teaching and learning in the Postlinguistic condition? In L. Alsagoff, S. L. Mckay, G. Hu, \& W. A. Renadya (Eds.), Principles and practices for teaching English as an international language. (pp. 47-66). New York, USA: Routledge. http://dx.doi.org/10.3167/latiss.2012.050101

Pennycook, A. (2009). Plurilithic Englihses: towards a 3D model. In K. Murata, \& J. Jenkins (Eds.)

Ploywattanawong, P., \& W. Trakulkasemsuk. (2014). Attitudes of Thai graduates toward English as a Lingua Franca of ASEAN. Asian Englishes, 16(2), 141-156. http://dx.doi.org/10.1080.13488678.2014.910902

Snodin. S. N. (2014). English naming and code-mixing in Thai mass media. World Englishes, 33(1), 100-111. http://dx.doi.org/10.1111/weng.12071

Snodin, N. S., \& Young, T. J. (2015). 'Native-speaker varieties of English: Thai perceptions and attitudes. Asian Englishes, http://dx.doi.org/10.1080/13488678.2015.1083354

Troyer, R. (2012). English in the Thai linguistic netscape. World Englishes, 31(1), 93-112. http://dx.doi.org/10.1111/j.1467-971X.2011.01742.x

Yano, Y. (2009). English as an international lingua franca: from societal to individual. World Englishes, 28(2), 246-255. http://dx.doi.org/10.1111/j.1467-971X.2009.01587.x

Watkhaolarm, P. (2005). Think in Thai, write in English: Thainess in Thai English literature. World Englishes, 24(2), 145-158. http://dx.doi.org/10.1111/j.1467-971X.2005.00399.x

\section{Copyrights}

Copyright for this article is retained by the author(s), with first publication rights granted to the journal.

This is an open-access article distributed under the terms and conditions of the Creative Commons Attribution license (http://creativecommons.org/licenses/by/3.0/). 